\title{
Mekânsal Değerinin Ötesinde Kültürel Bir Öge Olarak Pazar Yeri: Sanatçının Tuvallerinde Konumlari ${ }^{1}$
}

\section{Tuğba GÜNGÖR²}

$\ddot{O} z$

Birey her zaman kendini ifade etme arayışı içerisinde olmuş ve iletişim kurma yetisine yönelik birçok yöntem geliştirmiştir. Sanat gibi özel bir alanının keşfiyle gelişen süreçte, eserlerin çıkış kaynağına sanatçının yerel değerlerde gelişen çevresine dair gözlemleri, yaşanmışlıkları ve günlük yaşam dinamikleri referans olabilmektedir. Bir gelenek yapısı ve gida, giyim, araç ve gereç gibi günlük temel ihtiyaçların karşılanmasında etkinlik alanı olan pazar yerleri sanatçının eserlerinde bir kültürel değer ve kültürler arası diyaloğu sağlayan unsur olarak kendi konumunu alabilmektedir. Çalışmada Çağdaş Türk Resim Sanatında varlığıyla kendini somutlaştıran "pazar yeri”" temalı eserler, plastik yaklaşımlar ve kültürel etkileşim noktaları açısından irdelenmiştir. Bu yolla kültürel bir dokuyu ifade eden pazar yeri temasının, eserlerdeki vücut bulma biçemleriyle varlığı sorgulanmıştır.

Anabtar Kelimeler: Pazar Yeri, Kültürel Öge, Çağdaş Türk Resim Sanatı

\section{The Bazaar as A Cultural Item beyond Its Spatial Value: The Artist's Positions On Canvas}

\section{Abstract}

The individual has always been searching for self-expression and has developed many methods for the ability to communicate. In the process that advances with the discovery of a particular field such as art, the artist's observations, experiences and daily life dynamics of the artist's environment that develops in local values can be a reference to the origin of the works. Bazaar, which is a traditional structure and an activity area for meeting daily basic needs such as food, clothing, tools, and equipment, can take their position as a cultural value and intercultural dialogue in the artist's works. In this study, the "bazaar" themed works that embody themselves in Contemporary Turkish Painting Art are examined in terms of plastic approaches and cultural interaction points. The existence of the bazaar theme, which expresses a cultural texture in this way, has been questioned with it styles in the artistic works.

Key Words: Bazaar, Cultural item, Contemporary Turkish painting art

\section{Atıf İçin / Please Cite As:}

Güngör, T. (2021). Mekânsal değerinin ötesinde kültürel bir öge olarak pazar yeri: Sanatçının tuvallerinde konumlar1. Manas Sosyal Araștormalar Dergisi, 10(4), 2243-2255.

Geliş Tarihi / Received Date: 09.03.2021

Kabul Tarihi / Accepted Date: 11.05.2021

\footnotetext{
${ }^{1}$ Bu çalışma, 3. Uluslararası Mehmet Başbuğ Sanat Araştırmaları (20-21 Şubat 2021) isimli sempozyumda sözlü bildiri olarak sunulmuş çalışmanın yeniden ele alınmış şeklidir.

2 Dr. Öğr. Üyesi - Süleyman Demirel Üniversitesi İletişim Fakültesi, gungortugba@hotmail.com

(iD ORCID: 0000-0001-5761-2807
} 


\section{Giriş}

Sanatçı, eserlerini üretirken esinlendiği kaynak noktalarının arasında kendi yaşanmışlıkları ya da çevresinden aldığı veri kaynaklarından beslenen gözlemleri olabilmektedir. Kendine çalışma alanı olarak yarattığ1 referanslar, zengin miras ve kültürel çeşitliliğin muhafızları olarak biçimlenebilmektedir. Geçmişi ve geleneği bir arada kendi kültürel potasında biriktirerek ve çağdaş kolektif bir değer olarak özgün yorumlarla sunabilmek, duyarlı sanatçı anlayışının düşünsel tohumlarından ortaya çıkmaktadır. Pazar yeri, geleneğin kültür taşıyıcısı olan mekân ve etkinlik ortamı olarak kaçınılmaz biçimde sanatçının tarihsel belleğinde yer etmektedir. Toplum içinde sosyal yaşantının sürekli karşılaşılan dinamiği olarak pazar yeri kavramı bireyin karşısında kültürel boyutuyla oluşum göstermektedir. Toplumların gida, giyim, araç ve gereç gibi temel ihtiyaçlarını karşıladığı pazar yeri, tarihsel olarak incelendiğinde sosyal yaşamda vücut bulduğu ve halen günümüze aktif şekilde taşındığı görülmektedir.

Varlık bulduğu günden bu yana, pazar yerleri, yerleşim bölgelerinin hem ekonomik yansımasına hem de kültürel dokusuna dair ciddi veriler sağlayan, ticari özelliğinin ötesinde kültürel anlam taşıyan ve sosyal yönünde ağıllı̆̆ı olan yapıyı vurgulamaktadır. Yaşanılan çağda tüketim alışkanlıklarımızdaki biçimlerin hızlı değişimine rağmen, günümüzde hala varlığını sürdürmekte ve insan yaşamının sosyal dinamikleri arasında önemini korumaktadır.

Temel anlamda gereksinimden doğan edinim olarak alıcı ve satıcının tarafları olduğu alışveriş olgusu, karşllığ olan ürünün kullanımı ya da mülkiyetinin taraf değiştirmesini ifade etmektedir. En ilkel anlamda trampa yöntemiyle yapılarak, yeni formlarıyla günümüze kadar uzanmıştır. Bu uygulamada, ürün veya hizmete karşılık yine ürün veya hizmet vererek gerçekleşmiş (Tokol, 1996, s. 3), devamında birçok yapısal değişikliğe uğrayarak güncel niteliğine ulaşmıştır. Yaşanılan çağın getirdiği yeni düzen anlayışı, gelişen malzeme olanakları, ekonomik seri üretim ve tüketim alışkanlıklarılyla değişen yaşam dinamikleri, alışveriş eyleminin geleneksel anlamda kamusal alanlardaki temel formunu oluşturan pazar yerlerinin sosyal konumunu sarsamamıştır. Giyim-kuşam, gıda, araç gereç gibi kimi malzeme ihtiyaçlarının giderildiği bu ortamlar sosyal hayatın ortak buluşma alanlarını ifade etmektedir.

Hem eylemsel olarak alışverişi hem de mekân olarak tematik ya da süreli pazar yerini tanımlayan pazar kavramına ve kimi zaman bütünleştiği pazar yeri kavramının tanımlarına çeşitli yaklaşımlarla bakmakta fayda görülmektedir. Haftanın bir gününü, iktisadi kavram olarak piyasa ve hatta ulusal ya da uluslararası potansiyel mal satımı yapılabilen sürüm yeri gibi farklı anlama gelen tanımları barındırmakla birlikte, çalsşılan konu bağlamında özelleştirilmiştir. Söz edilen tanımlamalarda pazar ve pazar yeri kavramları pazar tanımı altında birlikte yer alırken kimi tanımlarda ayrılmaktadır. Çalışmada tanımlama yaparken her iki kavram da tanımlama yapılan kaynaklarda birlikte yer aldığı şekilde aktarılmıştır. Haftanın belirli günlerinde kurulan ve çeşitli şeylerin satıldığ1 alısveriş merkezi/belli şeylerin satıldığ1 yer/üstü açık alışveriş mahalli/alısveriş (Doğan, 1981, s. 807); satıcıların haftanın belirli günlerinde bir araya gelerek mallarını sergileyip sattıkları kamuya ait yer/alım satım işleri: alışveriş/tek tip malın veya ürünün satıldığı üstü kapalı ya da açık alan/pazar kurulan alan (Çağbayır, 2007, s. 3805-3806), çarş1, pazar/alışveriş (Kanar, 2009, s. 2698); belli bir şeyin satıldığı yer/belli bir günde her türlü mal satıcılarıyla alıcıların toplanıp alışveriş ettikleri yer/alısveriş/pazar kurulan alan (Büyük Sözlük, t.y., s. 1696-1697); belirli malların geçici bir süre için satışa sunulduğu sergi alanı (Ana Britannica, 2004, s. 495); dükkanlarda veya açık tezgahlarda bulunan malların alınıp satıldığı, üzeri kapalı veya açı olan yer/satıcıların mallarını satmak için haftanın belirli günlerinde bir yerleşme merkezinde kurdukları geçici sergilerin yeri/belli bir şeyin satıldığ yer/alışveriş, alım satım (Büyük Lügat ve Ansiklopedisi, 1990, s. 952); satıcıların belirli günlerde yiyecek maddelerini ve kimi malları satmak için bir araya geldikleri kamuya ait alan/alım satım, alısveriş/tek tip malın satıldığı üstü kapalı ya da açık yer (Büyük Larousse, 1986, s. 9238); pazar/alışveriş; alışveriş yapılan yer (Toven, 2004, s. 592); üstü açık meydan gibi alanlarda kurulan geçici alışveriş yeri. Çoğunlukla süreli ve düzenli aralıklarla kurulmaktadır. Tek bir malın satımı için kurulabileceği gibi, mahalle ve kent ölçeğinde her tür malın satışı için de kurulabilmektedir (Sözen ve Tanyeli, 2001, s. 188). Günlük dilde alıcı ve satıcıların mal değiş tokuşunda bulunmak üzere belli sürelerle bir araya geldikleri yeri anlatmaktadır ve bu anlamda panayırlar, fuarlar, sergiler ve salonlar, pazar kavramı içinde dâhil olmaktadır. Kavram belli bir yerde zamanda ve dolaysız olarak karşı karşıya gelmeyi barındırmaktadır (Büyük Ansiklopedi, 1990, s. 4474); pazar yeri/çarşı veya azar, alışveriş edilen yer (Nişanyan, 2007, s. 376). Tanımlara bakıldığında pazar kavramı hem eylemsel olarak alışverişi hem de alışveriş eyleminin geçtiği alanı vurgulayan pazar yeri kavramını kapsadığ1 görülmektedir. Öyle ki kimi tanımlamalarda çarşı kavramıyla eş değer tutulmaktadır. 
Toplumsal hayatın kazanımlarında yer alan, geleneğin temsilcisi olarak hizmet veren pazar kültürü geçmiş ve günümüz arasında nitelikli bir bağ oluşturmaktadır. Geleneksel bir alısveriş alanını ifade eden pazarlar, günümüze kadar satıcı, ürün ve alıcının buluştuğu bir anlatıyı temsil etmektedir.

Organize alışveriş sisteminin geliştiği pazar yeri mekânlarının geçmişine değinilerek örneklendirildiğinde antik çağda eski Yunan medeniyetinde şehrin aşağı bölümünü temsil eden agorada gerçekleştirildikleri görülmektedir. Eski Roma ve Bizans döneminde de devam eden bu gelenek aynı zamanda bir sosyal hareketliliğin de altını çizmektedir. Ortaçağ kentlerinde sur içinde düzenlenen pazarların varlığından söz edilebilmektedir (Tokol, 1996, s. 7-10). Anadolu'da bugünkü pazarların konumu ve biçimi epeyce değişmesine rağmen oldukça eskiyle tarihlenmektedir. Eskiden surlarla çevrilmiş kentlerin içinde tarım ürünlerinin satışı yasaklanmış olmasından, çevredeki kırsal yerleşmelerden gelen satıcılar ürünlerini kale kapılarının yanında belirlenen yerlerde satmışlardır (Ana Biritannica, 2004, s. 495). Devam eden süreçte yeni biçim ve konumlarına ulaşmıştır. Anadolu Türk şehirlerinde yiyecek içecek gibi maddelerin satıldığı pazar yeri, özellikle küçük şehirlerde camiler etrafında kurulmuştur. Muhtemelen şehre yiyecek satmaya gelen köylü ve göçebelerin, büyük bir camide öğle namazı kilma isteği ve bununla beraber cami etrafında toplanacak kalabalı̆ı̆n alısverişe katılması düşüncesinin olması bu fikri oluşturmaktadır. Geçici olan bu pazar yerleri, büyük şehirlerde eylemlerinin türüne bağlı olarak, tahıl pazarı, hayvan pazarı gibi kategorilere ayrılmıştır. Geçici pazar yerleri, şehirle köy ve göçebe arasındaki ilişkilerin, günümüze kadar devam eden ifadesi olabilmiştir (Kuban, 1968, s. 72). Eski Türk kentlerinde çeşitli günlerde oluşturulan pazarlar alışverişin haricinde iletişim merkezi olarak görev yüklenmiştir. Günümüzde hal, market, kapalı pazar gibi daha uzmanlaşmış tarımsal ürün satış yerlerinin bulunmasına rağmen, büyük kentlerde bile semt pazarları hala ucuz alışverişin yapılabildiği yerler olma özelliğini korumaktadır (Ana Biritannica, 2004, s. 495). Günümüzde, amaca, sosyo-kültürel duruma, mimari ve coğrafi konuma, çevresel koşullara bağlı olarak şekillenebilen pazar yerleri, her türlü değişime yönelik esnekliğini koruyarak hayatın akışı içinde insanın yaşam biçimine, kültürel birikimlerine dair veri sağlayıcısı olmaktadır. Yaşamdan kesitlerin filtresiz olarak sunulduğu bu alanlarda beşerin en masum ve yalın hallerinin canlı örnekleri görülebilmektedir. Pazar coşkusu, kalabalığın uğultusu, yaşamı sürdürmeye ya da daha nitelikli hale getirmeye dair ürüne ulaşabilme tutkusu, insanın varoluşunun gizil kültürel kanıtını sonsuzluğa taşımakta ve belleklerde yer edindirmektedir. Sosyal yaşamda önemini koruyan pazar yerleri, yaşamın tanığı olan sanatçı aracılığıyla kültürel bir gerçeklik olarak somutlaştırılmaktadır. Çağdaş Türk Resim sanatında birçok sanatçının yorumlarıyla, zengin mirasın coşkun esinlenme kaynağı olan pazar yeri temalı eserler belge niteliğinde önem taşıyarak ebedileşmektedir.

\section{Mekânsal Değerinin Ötesinde Kültürel Bir Öge Olarak Pazar Yeri: Sanatçının Tuvallerinde Konumları}

En ilkel dönemlerden bugüne sosyal hayat içinde var olan birey için önemli yeri olan pazar kavramı geleneksel çizgiye ve kültürel bir olguya dayanmaktadır. Toplumun kültürel hafızasının temsil mekânı olan pazar yeri, sanatçının duyarlılı̆ında günlük hayatın gerekliliğinden biçim bulan kesitler olarak ortaya konulabilmektedir. Çeşitli teknik, üslup ve bakış açılarıyla üretilen pazar yeri temalı eserler, bulunduğu ekonomik, sosyolojik, coğrafi ve mimari konumunun ötesinde ortak bir dilde kültürel anlam katmanlarına sahip olmaktadır.

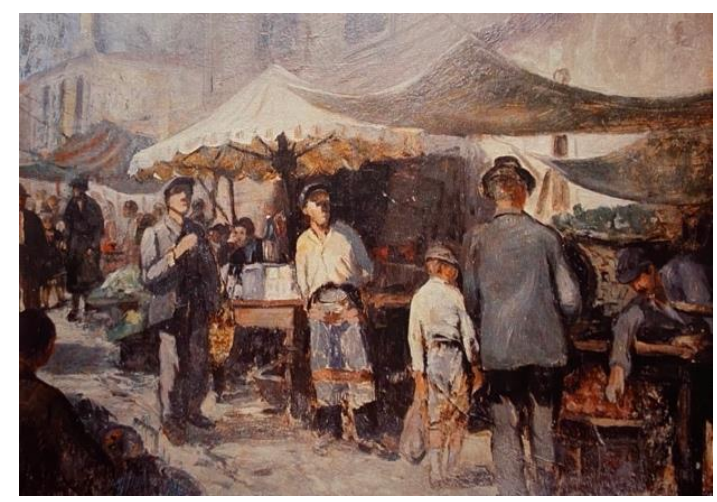

Resim 1. Üsküdarl Cevat (Göktengiv), Üsküdar Pąar Yeri (kesit), 1933, Duralit Üzerine Yağhl Boya, $48 \times 63$ cm, özel koleksiyon (Haydaroğh, 2003, s. 43). 
Gündelik yaşam ritüellerinin bir parçası olan pazarlar, Türk resim sanatında sıklıkla konu edinilen çalışmalar arasında olmuştur. Çok yönlü bir kişilik ve birçok beceri alanına sahip, Asker Ressamlar Kuşağı ve Hoca Ali Rıza ekolu sanatçılarından olan Üsküdarlı Cevat (Göktengiz) (1870) yaşamış olduğu bölgenin birçok sayıda farklı görünümünü aktaran eserler üretmiştir. Üsküdar dâhil olmak üzere birçok bölgeyi belge niteliğinde, içtenlik ve titizlikle çalışmalarına aktarmıştır (Sarıdikmen, 2005, s. 664). Hızla atılmış firça tuşeleri ve plastik etkileriyle izlenimci bir üslup içinde olduğu dikkati çekmektedir. "Üsküdar Pazar Yeri” isimli çalışmasında gündelik bir pazar yeri dinamizmi, yaşamla iç içe ve duygusal bir birlikteliğin izlerini sürmektedir. Güçlü bir desen anlayışı ve figürlerin yüzey üzerinde yerleşimleri çalışmanın estetik değerlerini arttırmakta ve sanatçının duyarlı kişiliğiyle birlikte gelişen gözlemleri alışılageldik bir durumu pentürel boyutta ortaya koymaktadir.

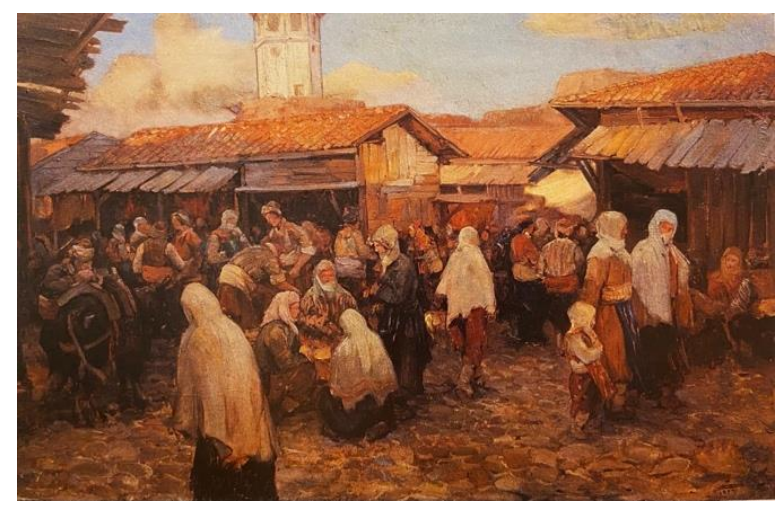

Resim 2. Sami Yetik, Ankara Saman Pazar, 1936, Mukavva Üzerine Yăgh Boya, 70x101,5 cm, Istanbul Resim ve Heykel Müzesi (Haydaroğlu, 2003, s. 49).

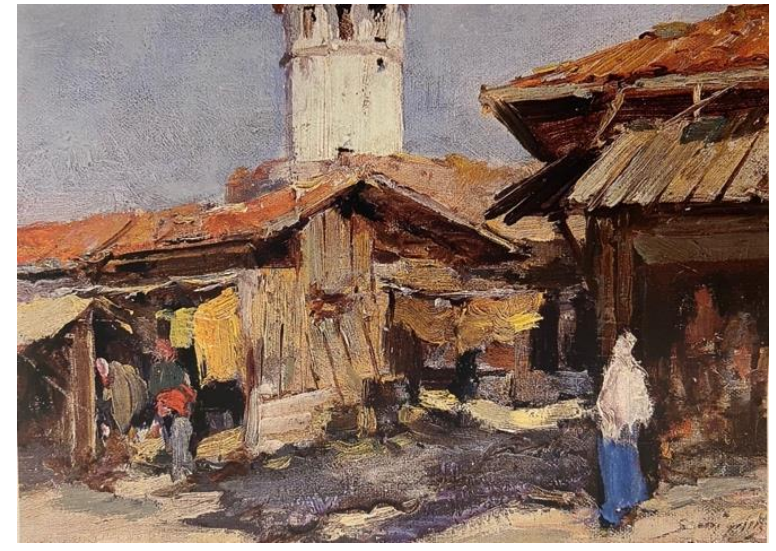

Resim 3. Sami Yetik, Eski Ankara'da Pazar, Tuval Üzerine Yağh Boya, $70 \times 100$ cm (Giray, 2000, s. 109).

Sami Yetik’in (1878) “Eski Ankara'da Pazar” isimli çalışması, üretildiği zamanın sosyal, ekonomik ve kültürel durumuna ayna tutmaktadır. Ankara’nın Koyunpazarı'nın betimlendiği çalışmada arka mekânda görülen saat kulesinin yükseldiği barakaların önlerinde kadınlar alışveriş yapar halde sunulmaktadır. Oldukça sade bir düzeyde gelişen pazarda tahta paravanlar ve güneşten korunmak için tahta gölgeliklerin kullanıldığ1 anlatı görsel şeffaflı̆̆ıyla gerçekleşmektedir (Giray, 2000, s. 108). Ekonomik gelişmişlik düzeyinin oldukça düşük olduğu, çaresizlik, zorluk gibi kavramların plastik etkilerle vurgulandığ1 çalışmada dramatik bir atmosfer yaratılmıştır. 


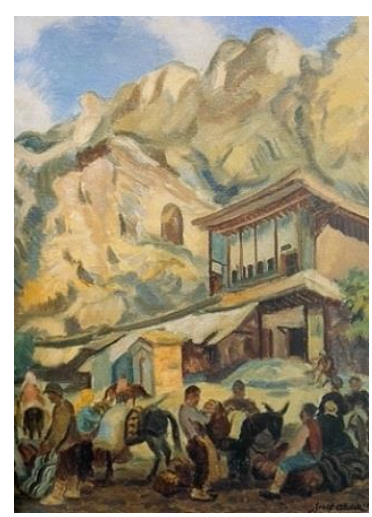

Resim 4. Şeref Akdik, Kütabya'da Paz̧ar (kesit), Tuval Üzerine Yağh Boya (Giray, 2000, s. 255).

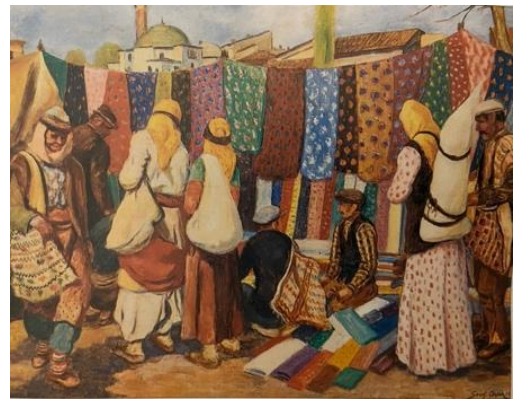

Resim 5. Şeref Akdik, Paz̧aryeri, Tuval Üzerine Yağh Boya, $99 \times 116$ cm (Ersoy, 2004, s. 20).

Şeref Akdik'in (1989) güçlü bir desen altyapısıyla ortaya koyduğu "Pazaryeri" isimli çalışmada, bir kumaş ve halı sergisi önünde alışveriş yapan kadınlar, yerde oturmakta olan satıcılarla pazarlık yapar haldedirler ve mekana ait mimari unsurlar dikkat çekerken, herhangi bir yer izlenimi oluşturmaktadır. Canlı, sıcak, dinamik bir pazar yeri atmosferini, satıma çıan ürünler, kırsal kesim insanının kıyafetleriyle aktarılan yerel ve otantik öğeler zenginleştirmektedir (Ersoy, 2004, s. 20). Oldukça canlı bir renk paletinden çıkan resimde formlar hareketli unsurlarla belirtilerek, yerel izleklere yönelen bir anlayış ortaya konulmuştur.

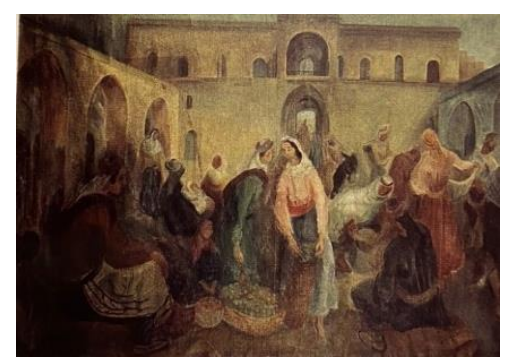

Resim 6. İlhami Demirci, Midyat Pažr, Twval Üzerine Yağh Boya (Giray, 2000, s. 376).

Ayrıntıc1 tarzı ve kendine özgü tekniğiyle yapıtlarını geliştiren İlhami Demirci'nin (1908) (Ersoy, 2004, s. 166), "Midyat Pazarı" isimli eserinde yalın ve arı biçim anlayışı sezinlenmektedir. Heyecanlı ve rahat firça kullanımıyla pazar yerinin coşkulu dinamizmini yansıtmaktadır. Umutla satış için müşterilerini bekleyenler, pazarlık yapanlar, satış yapılan malzemeleri inceleyenler samimi bir iç içelikle sunulmuştur. Yöresel kıyafetleriyle betimlenen figürler yönlendirici etkileriyle kompozisyona hareket katan unsurlar olmaktadır.

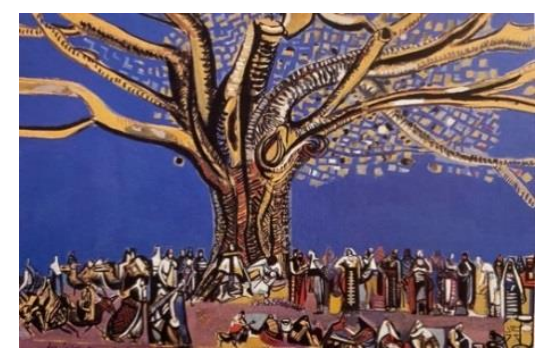


Resim 7. Eren Eyüboğlu, Pazar-Alışveriş, Tuval Üzerine Yă̆lı Boya (Giray, 2000, s. 376).

Sanat yaşamı boyunca birçok üslup araştırması içinde olan Eren Eyüboğlu (1913), kompozisyonlarında plastik unsurları kendi özgün üslubu içerisinde kurgulamıştır. "Pazar-Alışveriş" isimli eserinde geleneksel Anadolu kültürüne duyduğu ilginin yoğun izleri görülmektedir. Gelenekseli aşan tutumla renkçi bir anlayıșın görüldüğü eserde kalabalık bir figür grubu harmanlanmış, kişisel sanat üslubuna uygun olarak perspektif uygulamıştır. Oldukça yalın ve kontur çizgileriyle belirlenmiş tüm imgeler, tuval yüzeyinde konuya hizmet eden bir yerleştirmeyle konumlanmıştır.

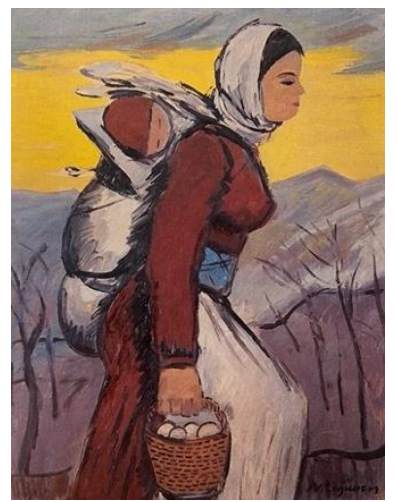

Resim 8. Nurettin Ergüven, Pazara Giden Yörük Kadın, Tuval Üzerine Yăğl Boya (Giray, 2000, s. 304).

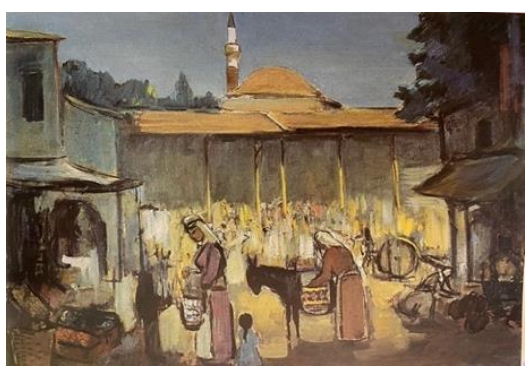

Resim 9. Nurettin Ergüven, Eski Ankara'dan Pazar Yeri, Tuval Üzerine Yağh Boya (Giray, 2000, s. 305).

Nurettin Ergüven (1905), deneye dayalı görünen kompozisyon çeşitlemelerinde soyutlamacı ilgilerle pekişen bir figür anlayışının buyruğunda eserler üretmiştir. Biçimci ve renkçi iradeyle geliştirdiği kompozisyonlarda, dinamik firça işçiliği öncelenerek öznel bir biçimleme tutumu ortaya çıkmıştır (Galerisoyut). "Eski Ankara'dan Pazar Yeri” isimli eserinde kaynağını yerel kültürden alan, çalışmanın hem isminden hem de görsel okuması yalın olmasından anlaşılan bir konu seçimiyle anlatımı güçlü bir sanatsal karakter ortaya çıkmaktadır. Eserde artistik bir biçimlendirmenin ötesinde, formlar birbirinden ayıklanarak hacimsel değerleri oluşturulmakta, toplumsal ve kültürel bir gelenek yapısı vurgulanmaktadır. Figürlerin hareketlerinden psikolojik bir anlatı üslubunda belirlenen göstergeler, yaşam döngüsü içinde gelişen bir eylemin kültürel çıktılarını aktarmaktadır.

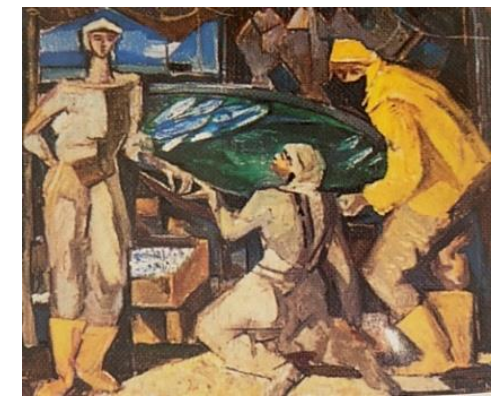

Resim 10.Turgut Atalay, Balıkçılar. Tuval Üz̧erine Yağlı Boya, $50 x 60$ cm. Taviloğlu Koleksiyonu (Ersoy, 2004, s.).

Turgut Atalay'ın (1918), toplumcu gerçekçi sanat edimiyle, çalışma konuları arasında yöresel konular yer almıştır. "Balıkçılar" adlı eserinde, gerçekçi bir iradenin oluşturduğu kompozisyonda tezgâh başında satış yapan balıkçılar gösterilmektedir. Geçim mücadelesi içinde çalışan balıkçılar, yaptıkları işin gereği olan giysiler içinde betimlenmiştir. Figüratif bir üslupla ve gerçekçi renk seçimleriyle form verilmiş bu çalışmada diz çökmüş bir kadın ile balıkçılar arasında süren pazarlık diyalogları figürlerin davranışlarından 
yordanabilmektedir (Ersoy, 2004, s. 66). Eser alımlayıcısına yaşamın nasıl üretildiğinin, gündelik yaşamda evlere ve hayatlara karışan zorlukların hikayesini örneklemektedir.

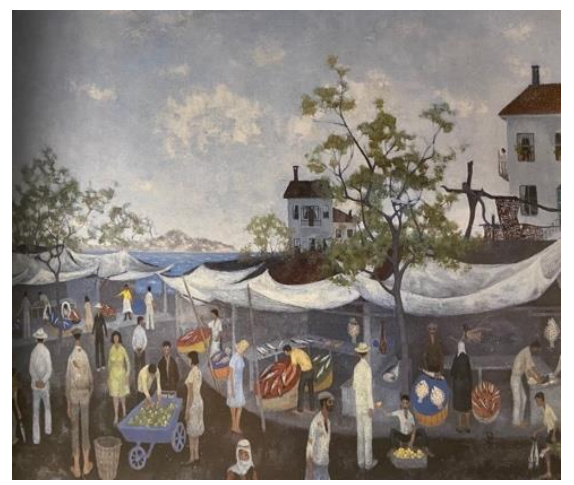

Resim 11. Nedim Günsür, Bahleç Pazar, Twval Üzerine Yağl Boya $53 \times 74$ cm (Giray, 2000, s. 491).

Nedim Günsür (1924), sanat çizgisinde ince eleyen, sık dokuyan, sabırlı, istikrarlı bir sanatçı olmuştur. Figürsel anlatımın yoğun olduğu eserlerinde ince ve uzun formlarla belirlenen her yaş ve kesimden insan naif bir tutarlılıkla işlenmektedir (Giray, 2000, s. 490). "Balıkçı Pazarı" adlı eserinde Günsür, kendi kompozisyon kurgusu içinde alışveriş yapan, satış yapan insanların aynı ortamda betimlemesinin yanı sıra izleyicisine farklı hayatlara dair bir yelpaze sunmakta, başkalarının hayatlarının gözlemlenmesine izin vermektedir. Statik ve kimi figürlerde neredeyse frontal bir katılıkta gelişen görüntüye karşılık, çalışma içerisindeki gelişen hayatsal titreşimler, zamanın geçiciliğinden öte diri ve kalıcı bir izlenim bırakmaktadır.

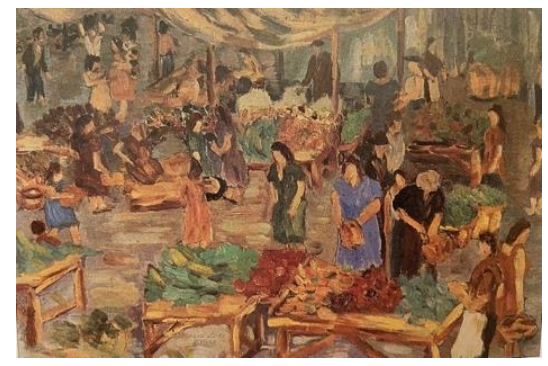

Resim 11. Salih Zeki, Pazaryeri, Twval Üzerine Yağh Boya, $25 x 45$ cm Ersoy, 1998, s. 505).

Kendine özgü üslubu içinde izlenimci ve figüratif anlayışta eserler üretmiş olan Salih Zeki'nin (1931), "Pazaryeri" isimli eserinde ayrıntılara takılmadan devinim içinde canlı, neşeli bir pazar yeri dinamizmi yansıtılmaktadır. Işık, renk ve hareketlilikle şekillenen bu spontan etkili çalısma, yaşam karmaşası içinde görülmesi kolay olmayan güzellik ve şiirsellikle betimlenmektedir. Telaşlı pazar yerinin canlılık halindeki atmosferi, renk lekeleriyle biçimlenmektedir (Ersoy, 2004, s. 505). Pazara gitmenin iç açıcıllğını, kişiler arası diyaloğun yaşattı̆̆ mutluluk duygusunu, taze ürünlerin canlı renkleri ve ortama saçılan kokusunu duyumsatmaktadır.

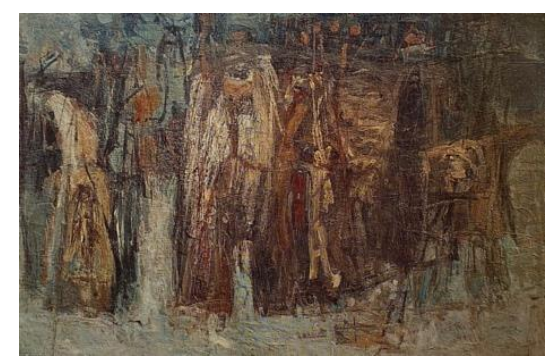

Resim 12. Mustafa Ayaz, Pazar Yeri İzlenimlerinden, 1967, Twval Üzerine Yağl Boya, 96×147,5 cm, İstanbul Resim ve Heykel Müzesi (Haydaroğlu, 2003, s. 198).

Mustafa Ayaz (1938), kendi yaşamından izler taşıdığı sanat serüveninde yetiştiği yörenin doğal yapısından, toplumsal ve kültürel değer yargılarından beslenmiş bir sanatçıdır (Gençaydın). Sanat eğitimini tamamladıktan sonra görevi için atandığı bölgede çalıştı̆̆ süre boyunca kağnılar, yöre insanları, kırsala dair görüntü ve izlenimlerden edindiği verilerden soyut ve yarı soyut eserler ortaya koymuş, Çorum pazar yerindeki kadın imgelerinin izleri sonraki çalışmalarında bile sürülmüştür (Özbaş, 2020, s. 58). Kendi iç 
gerçekliği kadar geleneksel olgulara yer verdiği çalışmalarında lirik soyutlamacı bir anlayış çizgisi görülmektedir. "Pazar Yeri İzlenimlerinden” isimli çalışmasında öznel bir anlayış sezilirken, doğa renklerine uygun bir skala seçilerek lekesel değerler ön plana çıkmıştır. Kendi sanatsal gelişim sürecine ve üslubuna eklemlediği konu seçiminin önüne resmin plastik etkileri çıkmaktadır. Fırça akışının oluşturduğu hareket, pazar yerinin dinamik yapısıyla oluşturulan canlılıkla örtüşmektedir.

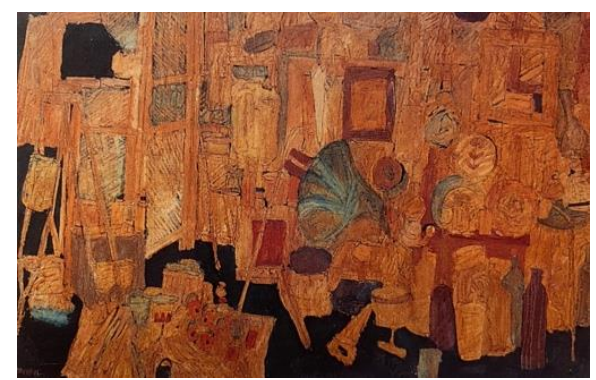

Resim 13. Mubsin Kut, İstanbul'da Pazar, 1967, Tuval Üzerine Yağh Boya, 96,5×147 cm, Ístanbul Resim ve Heykel Müzesi (Haydaroğlu, 2003, s. 199).

Kendine özgü üslubunda geliştirdiği ve çevreye ait gözlemlerini soyutlayarak sunduğu çalışmalarında renkçi bir anlayış gözlemlenen Muhsit Kut (1938) (Ersoy, 2004, s. 340)'un "İstanbul'da Pazar" isimli eserinde, sosyal ve kültürel yaşamdan imgeler bulunmaktadır. Siyah zemin üzerine sıcak renklerin ağırlıkta oluşturduğu kompozisyonda kimi imgeler kolaylıkla seçilebilmektedir. Günlük hayatta ev yaşamında sıklıkla karşılaşılabilen bu imgeler, konuyla bütünleşik referans nesnelerden oluşan parçalardır. Grafiksel bir tandansla oluşturulan formlar, mekânın ötelendiği, insan figüründen yalıtılmış bir sadelikte oluşturulmuştur. Betimlemelerin kalabalıklı̆̆ına tezat olacak yaklaşımla dinginlik ve tinsellik hâkim olmaktadir.

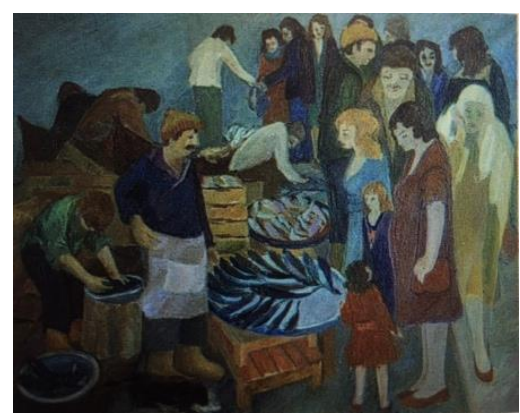

Resim 14. İsmail Avcı, Balıkęular, 1989, Tuval Üz̧erine Yağh Boya, $46 \times 55$ cm (Ersoy, 1998, s. 88).

İsmail Avcı'nın (1939) klasik figüratif üslup özelliğinde ürettiği eserlerinde desene her zaman öncelik verilmiştir. Sevgiyle ve hoşgörüyle sürdürdüğü sanatsal yaşantısındaki kimliğiyle yaşamın dinamizminin altını çizen eserler geliştirmiştir. Yürüyen, eğlenen, alışveriş yapan insanları yoğun bir devinim içinde betimlemekte, günlük yaşamdan kesitlerle İstanbul'un kozmopolit örüntülerini aktarmaktadır. Her türlü sosyal kesitten bireyler giyim ve davranışlarındaki çeşitlilikle bir arada betimlenmektedir (Ersoy, 1998, s. 88). Evrensel bir mekâna atıfta bulunan "Balıkçılar" isimli eserinde sadece zamanın sosyal yapısının kayıt altına alınmasını sağlamamış, günümüzde bile satılan ürünün aynı olmasının yanında kıyafet, alışveriş kültürü, davranış biçiminin benzer özellikte görülebilmesiyle eseri zamansız kılabilmiştir.

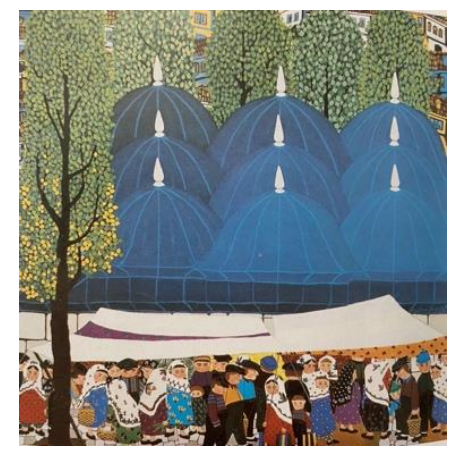

Resim 15. Oya Zaim Katoğlu, Heryerde Pazar, Tuval Üzerine Yă̆lı Boya, $80 x 80$ cm (Ersoy, 2004, s. 312). 


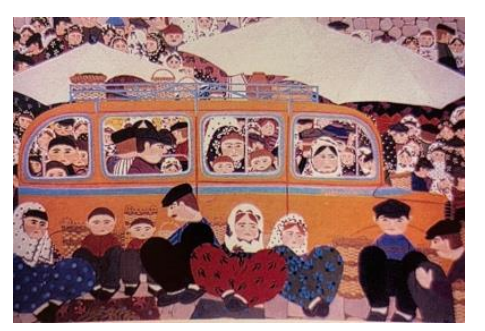

Resim 16. Oya Zaim Katoğlu, Paz̧ar Yorgunluğu, 1990, Twval Üz̧erine Yağh Boya, $70 \times 100$ cm (Ersoy, 1998, s. 165).

Gördüğü ve görmek istediği, düşlediği bir dünyanın resimlerini yapan Oya Zaim Katoğlu (1940), bilinen nesneleri şeffaflık içinde ve samimi bir duygusallıkla şematize edip, üst üste istifleyerek ve ş̧ıktan yalıtılmış bir boyama yöntemiyle betimlemiştir (Ersoy, 1998, s. 165). Minyatür etkili ve bir nakış gibi işlediği "Pazar Yorgunluğu" isimli çalışmasında kalabalık bir figür grubu kullanılmıştır. Yorgunluk gibi negatif bir kavramı eser isminin bir parçası olarak kullanmasına karşın canlı renk paletindeki seçimleri resme dinamizm katan ayrı bir öğe olarak konumunu almıştır. Çok renkli ve bezemeci bir üslubun etkisiyle çalışılan eserde pazar ritüeline ait imgeler kullanılmıştır.

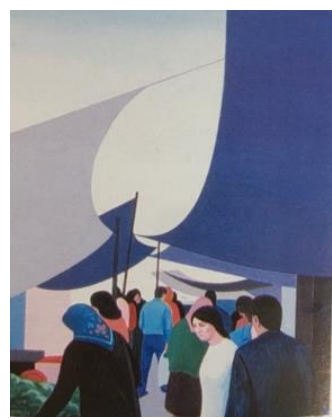

Resim 17. Nevbahar Aksoy, Pazaryeri, Tuval Üzerine Yağh Boya, $70 x 50$ cm (Ersoy, 1998, s. 92).

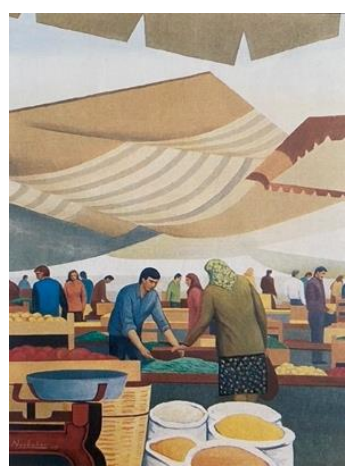

Resim 18. Nevbahar Aksoy, Pazar, Twval Üzerine Yağh Boya, $70 \times 50$ cm (Ersoy, 2004, s. 29).

Nevbahar Aksoy (1952), "Pazar" isimli çalışmasında, geleneksel halk pazarını düzenli geometrik bir kurgu içinde göstermektedir. Pazar yerinin karmaşasından farklı dinamik devinimi, dondurulmuş bir etki yaratmaktadır. Yeni bir düzen anlayışı içinde kurgulanan figürlerle, düz uygulanan boyama tekniğiyle birlikte, sade, yalın formlarla, gölgesiz olarak hassas bir titizlikte işlenmiştir (Ersoy, 2004, s. 29). Günümüzde bile görülmeye alışı olunan, satışa sunulmuş pazar ürünleri, sunum şekli, tartı, tente gibi malzemeler ve hatta pazarda gerek satıcı gerek alıcıların giyim stilleri güncelliğini korumaktadır. Dondurulmuş ve belleğe kaydedilmiş bir anı anımsatan çalışma, üretildiği tarihten yaşanılan bu ana, tazeliğini koruyarak aktarılmıs ve hiç de yabancısı olunmayan güncel bir görünümü bünyesinde taşımaktadır. 


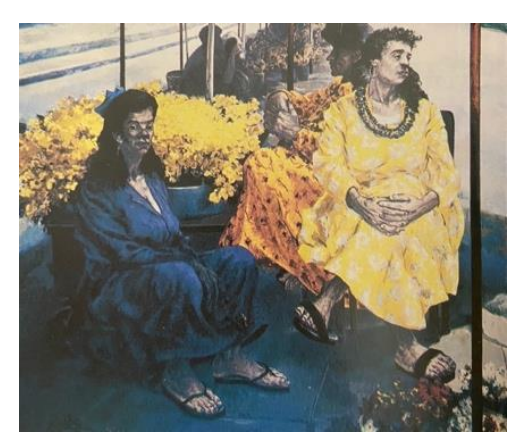

Resim 19. Nedret Sekban, Çiçekçiler, Tuval Üz̧erine Yağl Boya (Ersoy, 2004, s. 422).

1970’li yıllarda figüratif çalışmalar yapan Nedret Sekban'ın eserlerinde (1952), “insan” olgusu tüm yönleriyle aktarılmak amacında olunan mesajın özünü oluşturmaktadır (Ersoy, 1998, s. 92). Son yıllarda İstanbul kent yaşamından seçtiği konular içinden çingeneler, balıç̧lar gibi daha çok düşük sosyodemografik yapıdan betimlemeler sunmuş ve gruplar halinde bir araya getirmiştir (Ersoy, 2004, s. 422). Sanatçının "Çiçekçiler" isimli eserinde satış için bekleyen sadece çiçekler olmamaktadır. Müşterilerini bekleyen çiçekçiler, hayatın içinden samimi bir duruşla bezgin ve yorgun halleriyle çiçeklerin diri görüntüsüne tezat oluşturacak şekilde betimlenmektedir. Kültürel geçmişlerini, etnik kökenlerini giydikleri giysi, taktıkları aksesuar ve duruşlarıyla duyumsatan sanatçı, insana özgü gerçekliği tüm umuduyla birlikte aktarmıştır.

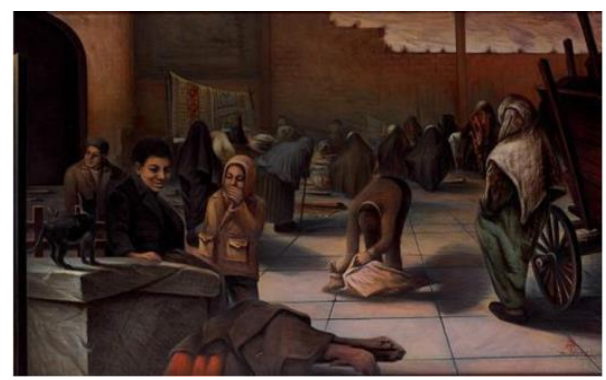

Resim 20. Aydm Ayan, Pazar Yeri, 2002, $100 \times 160$ cm, Tuval Užerine Yağh Boya (Kocabey, 2017, s. 48).

Figüratif anlayış üzerine kurguladığı çalışmalarında, simgesel bir sanat dili kullanan Aydın Ayan (1953), entelektüel donanımıyla eserlerini yaratıcılığını eklemleyerek, işaretler, renkler ve plastik değerlere kattığ1 tinsel katmanlarla oluşturmaktadır (Ersoy, 2004, s. 74). Sanatsal serüveninde istikrarlı olarak toplumsal gerçekçi-eleştirel gerçekçi anlayışını farklı temalarla sürdüren Ayan, izleyicisini düşündürmeye yönelik simgeci anlatım olanaklarını geliştirmiştir (Arda, 2007, s. 178-179). Türk insanının yaşamına dair gerçeklerini kendi birikimleriyle harmanlayan sanatçının "Pazar Yeri” adlı çalışmasında yaşamın tanıklığına şahit olunan öyküsel bir anlatım oluşturulmuştur. Mekân içinde hayvan ve insanın kurgusal birlikteliği, çok boyutlu biçemiyle özgün bir yaklaşım sergilemektedir. Yaşam mücadelesinin sınırlarının zorlandığı çalışmada kullanılan renk seçiminde koyu ton ağırlıklı gerçekleştirilen tasarımın içinde oluşturulan tezatlıklar yaşamın içinden bir gerçekliğin kanıtını sunmaktadır.

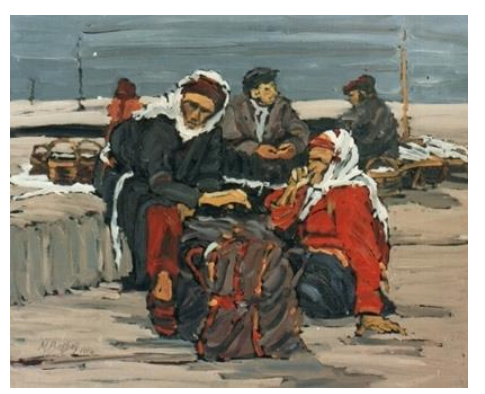

Resim 21. Mehmet Başbuğ, Pazar Yerinde, $50 x 60$ cm, Tuval Ǚerine Yağli Boya, 1984, Özuel Koleksiyon. 


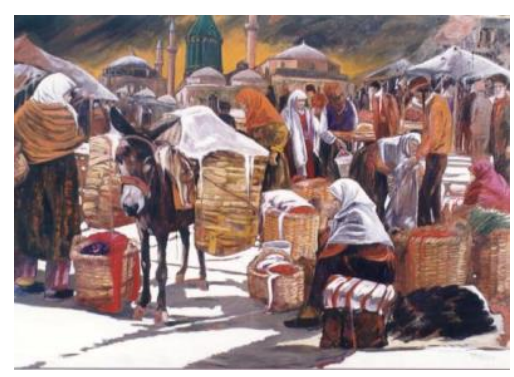

Resim 22. Mehmet Başbuğ, Konya'da Paz̧ar, 140×200 cm, Twval Užerine Yağh Boya, 2001, Konya Polis Evi.

Mehmet Başbuğ (1956), Türk kültür ve dünyasına ait yaşanmışlıkları insani bir duyarlıkta ele almıştır. Anadolu insanının sosyolojik ve kültürel yapısını saf ve samimi anlatım tarzıyla incelikli bir şekilde işlemiştir. Arka plana Kubbe-i Hadra (Yeşil Türbe) gibi Türk kültür dünyasının önemli bir simgesinin dahil olduğu "Konya'da Pazar" adlı çalışmada, pazar yeri karmaşasının coşkusu tüm içtenliğiyle duyumsanmaktadır (Güngör, 2018, s. 200). Başbuğ’un resimlerinde Anadolu gerçeği olarak yansıtılan bekleşen, kahvede oturan, pazar yerlerinde alş̧veriş yapan insanlar dikkati çekmektedir. Bu insanlar, hangi coğrafyada yaşarlarsa yaşasınlar, kültürel bir yansımanın kahramanları şeklinde tuvale yansımıştır (Başbuğ, 2017, s. 65). Eserlerindeki insan teması, figür resmine bağlılığını güçlendirmiş, Anadolu yaşam tarzını ve kültürünü yapitlarında bolca yansıtan Başbuğ (Başbuğ, 2017, s. 29), Anadolu yaşam kültürüne ait imgeleri güçlü desen altyapısıyla kurgulamış, çalışmalarındaki figürlerin portrelerinde içinde bulundukları duygu durumlarını ortaya koymuştur. Kendi üslubunu yaratarak başlı başına bir ekol olan sanatçının çalışmasında, biçim, öz ve içerik dengesinin bütüncül uyumu konu akışının niteliğini arttıran işlevsel öğeler olmaktadır. Kültürel dokunun zenginliğini, sanatçının bakış açısı, nitelikli gözlemciliği ve sanatsal öğretisinin yaratım çıktları arttırmaktadır.

\section{Sonuç}

Yaşamın başlangıcıyla birlikte kendini ifade etme yollarını arayan birey için sanatsal alanın keşfi hayata dair kesitlerin temsil edilebildiği öznel bir yaratı mekanizmasının doğmasını sağlamıştır. Sanatçılar var oldukları toplum ve kültür içinde gözlem yetenekleriyle iyi birer yansıtıcı olmaktadırlar. Toplumun ve kültürün dinamiklerine ayna tutarak bireysel perspektiflerinden ele almaktadırlar. Sanatçının gelişmesinde, içinde yetiştiği coğrafyanın sosyal yapısı, insani ilişkileri, düşünce sistematiği, kültürü etkili olmaktadır. Bu kanallardan edindiği izlenimler aracilığıyla kendi duyarllığında elde ettiği verileri sentezlemektedir. Harmanladığı bilgilerle üretimlerinde yaşam biçimlerine dair ipuçları vermektedirler. Toplumun ve kültürün karakterini, yaşamın günlük örüntüleri arasında var olan gelenek yapısını saflaştırılmış haliyle aktaran sanatçı kendi biçem dilini geliştirerek kurgulamaktadır. Kültürel bir anlam taşıyıcısı, geçmiş ve yaşanan an arasındaki köprü olarak pazar yerleri beşer için ticari bir faaliyet alanının ötesinde değer taşımaktadır. Satııı-ürün-alıcı denklemi salt terminolojik yapısının sınırlarını aşan işleviyle pazar yeri mekanlarında çok işlevli bir organizasyonu teşkil etmektedir. Bireyin kendiyle ve yaşamla temas kurduğu bir alan olan bu mekanlarda kültürel anlamda çok sesli bir kaynak oluşmaktadır. Pazarın cıvıltısı, telaş1 içinde alım satım yapan insanlar kendi kültürel öz benliklerine dair doku oluşturmaktadırlar. Yaşam içinde birçok katmandan gelir düzeyine sahip bireylerin günümüzde bu müşterek alanlarda bir araya gelmelerine ve sosyal hayat içinde geleneksel kültür yapısının devamının sağlanmasına aracı olmaktadır. Kültürel ve toplumsal bir teşkilatlanmanın içinde yaşayan sanatçı için, birçok kesimden insanın bir araya geldiği pazar yerleri yaratımlarında çıkış noktası olabilmektedir. Sanatçıların yapıtlarında bireylerin kültürel, sosyal, ekonomik durumları hakkında kesitler görülmektedir. Türk resim sanatı içerisinde değerli eserleriyle pazar yeri teması üzerinde çalışan birçok sanatçı bulunmaktadır. Pazar yeri temalı eserler kültürel boyutları ve sanatçının plastik yaklaşımı çerçevesinde irdelenmiştir. Çalışmalarıyla kültür belgeselciliği yapan sanatçıların kendi sanatsal üslupları doğrultusunda eserlerini oluşturdukları görülmektedir. Duyarlllıklarıyla yaşamdan elde ettikleri izlemlerin tinsel bağını kurdukları eserler aracıllğıyla kültürel imgeler yansıtılmaktadır. Kimi eserlerde coşkun, neşeli, canlı, dinamik bir yaklaşım görülürken, kimilerinde yaşamın zorlu mücadelesi, hayat içinde var olma savaşı dramatik bir hava içinde aktarılmaktadır. Hem plastik hem de kurgusal yaklaşımları açısından birbirinden farklılaşan eserler çağdaş Türk resminin temsilcileri tarafindan arşiv niteliğinde, sonraki kuşaklara aktarılacak değerli ve zengin bir mirasın tözünü oluşturmaktadır. 


\section{Etik Beyan}

"Mekânsal Değerinin Ötesinde Kültürel Bir Öge Olarak Pazar Yeri: Sanaţ̧ınn Tuvallerinde Konumlar”" başlıklı çalışmanın yazım sürecinde bilimsel kurallara, etik ve alıntı kurallarına uyulmuş; toplanan veriler üzerinde herhangi bir tahrifat yapılmamış ve bu çalışma herhangi başka bir akademik yayın ortamına değerlendirme için gönderilmemiştir. Bu araştırma doküman incelemesine dayalı olarak yapıldığından etik kurul kararı zorunluluğu bulunmamaktadır.

\section{Kaynakça}

Ana Britannica (2004). Ana Britannica ansikelopedisi. İstanbul: Ana Yayınc1lik.

Arda, Z. (2007). Sanat eğitimcisi ve ressam Aydın Ayan'ın resimlerine estetik bir yaklaşım (Doktora Tezi). Selçuk Üniversitesi Sosyal Bilimler Enstitüsü, Konya.

Başbuğ, F. (2017). Türk dünyası ressamı Mehmet Başbuğ’un düşünce izleri üzerine. Türk Yurdu Dergisi, 106(360), 6566.

Başbuğ, F. (2017). Mebmet Başbuğ Bozkırdaki Atlar/Desenler. Ankara: Artsürem Yayınları.

Büyük Ansiklopedi (1990). Büyük ansiklopedi. İstanbul: Milliyet Yayınlar1.

Büyük Larousse (1986). Büyü̈k Larousse sözlïk ve ansiklopedisi. İstanbul: Gelişim Yayınları.

Büyük Lügat ve Ansiklopedi (1990). Büyük Lügat ve Ansiklopedi ansiklopedisi. İstanbul: Meydan Yayınevi.

Büyük Sözlük (t.y.). Büyük sǫ̈lïke ansiklopedisi. İstanbul: Arkın Kitabevi.

Çağbayır, Y. (2007). Ötüken Türkse söəlïk. İstanbul: Ötüken Yayınevi.

Doğan, M. (1981). Büyük Türkçe sǫ̈lïkk. Ankara: Birlik Yayınları.

Ersoy, A. (1998). Günümür Türk resim sanatı (1950'den 2000'e). İstanbul: Bilim Sanat Galerisi.

Ersoy, A. (2004). 500 Türk sanatçısı plastik sanatlar. İstanbul. Altın Kitaplar Yayınevi.

Galeri Soyut (2021). Nurettin Ergüven. Erişim Adresi: https://www.galerisoyut.com.tr/artist/nurettin-erguven/ galerisoyut.com. Erişim Tarihi: 14.02.2021.

Geçaydın, Z. (2021). Mustafa Ayaz. Erişim Adresi: https://www.mustafaayaz.com/tr/page/makaleler. Erişim Tarihi: 13.02.2021.

Giray, K. (2000). Türkiye Iss Bankası resim koleksiyonu. İstanbul: Türkiye İş Bankası Kültür Yayınları.

Güngör, T. (2018). 1980 sonrası Türk resim sanatında figüratif eğilimler ve Mebmet Başbuğ (Sanatta Yeterlik Tezi). Akdeniz Üniversitesi Güzel Sanatlar Enstitüsü, Antalya.

Haydaroğlu, M. (Edt.). (2003). Sanat dünyamıঞ. İstanbul: Yap1 Kredi Kültür ve Sanat Yayınları.

Kanar, M. (2009). Osmanl Türkesesi sözliügü. İstanbul: Say Yayınları.

Kocabey, E. (2017). Türk Resim Sanatinda akademisyen sanat eğitimcilerin dişavurumculuk hakkendaki görüsleri ve eserlerinin incelenmesi (Yüksek Lisans Tezi). Pamukkale Universitesi Eğitim Bilimleri Enstitüsü, Denizli.

Kuban, D. (1968). Anadolu-Türk şehri: Tarihi gelişmesi, sosyal ve fiziki özellikleri üzerinde bazı gelişmeler. Vakııflar Dergisi, 7, 53-73.

Nişanyan, S. (2007). Sözlerin soyağacı çağdaş Türkesenin etimolojik sözlï̈̆̈̈̈. İstanbul: Adam Yayınları.

Özbaş, N. A. (2020). Mustafa Ayaz’in hayatı ve sanatı (Yüksek Lisans Tezi). Ege Üniversitesi Sosyal Bilimler Enstitüsü, İzmir.

Sarıdikmen, G. (2005). Ressam Üsküdarlı Cevat (Göktengiz). İçinde Z. Kurşun, A. E. Bilgili, K. Kahraman, C. Güngör ve S. Ünlü (Edt.), Üküdar sempozyumu II (ss. 655-676). İstanbul, Üsküdar Belediye Başkanlığ1 Üsküdar Araştırmaları Merkezi Yayını.

Sözen, M. ve Tanyeli, U. (2001). Sanat kavram ve terimleri söఇlüğ̈̈. İstanbul: Remzi Kitabevi.

Tokol, T. (1996). Aliş-veriş merkęleri, çevre ve mekan ilişkisi (Yüksek Lisans Tezi). Marmara Üniversitesi Sosyal Bilimler Enstitüsü, İstanbul.

Toven, M. B. (2004). Yeni Türkęe lügat. Ankara: Türk Dil Kurumu Yayınları.

\section{EXTENDED ABSTRACT}

Since the beginning of human history, the individual has been in search of self-expression. For this, many methods have been developed for the ability to communicate. With the discovery of an artistic expression field, the artist's observations of his environment can be a trigger in the creation of the works. The artist's experiences with life and the dynamics of daily life are among the factors that enable the development of the creative process. The development of the artist as a social individual is influenced by the geography in which he was born and lived, as well as by the dynamics of the culture and society surrounding him. In the life pattern, the artist can feed on his own culture and the social structures he is in, in the data he conveys through his productions. For the artist, whose area of existence is naturally influenced, life achievements shaped by the cultural codes required by the dynamics of social life can appear as a subject area in the works. Artists are good observers of society. They convey the structure of the society and culture they live into their receiver through their works. They reflect the forms of society and culture according to their perspective. The artist, who is influenced by interpersonal relationships, 
ways of thinking, social and cultural structure, derives inferences about life. The impressions he gets from these variables are synthesized in his sensitivity. Parts of life and culture are embodied by transforming the blended data into artistic expressions. In his designs, which he creates with his unique artistic expression language, the cultural character, the structure of tradition developed in the social life order are determined in a purified form.

The bazaar that connects the past and the present in the cultural layers has a meaning beyond the commercial action field for the individual. These spaces, where basic needs are met, have taken an active place in social life in the historical development process and have been actively carried to the present day. While it mirrors the reflections of the economic structures of the regions where the societies have settled, it presents a lot of data regarding the cultural texture since the day it emerged. Features such as the lifestyle of the people of the region where the bazaar is established, shopping rituals, bazaar product range, and architectural structure provide information about the identities of these areas. It transcends the boundaries of the commercial field in its social and cultural aspects. The phenomenon of shopping is based on a basic necessity in essence. In the most basic sense, the parties are the buyer and the seller. The use or ownership right of the product within this application changes the party. It is based on the change of another structure that corresponds to the product from the beginning. Today, it has reached its new forms. The rapid change of the scheme in the consumption habits of the current age has not undermined the value of bazaar in individual and social life. The development of material possibilities in daily life conditions, the increasing demand for mass production and consumption have not changed the traditional form of shopping activity taking place in the bazaars. Nowadays, it adapts to all kinds of conditions, creates a flexible shape, and allows sections of life to be seen without a filter. The act of shopping goes back to the past as much as human history and refers to the cultural dimension of the tradition. The equation that develops in the trivet of seller-product-buyer turns into multi-functional organizations. In these places, the individual comes into contact with himself and life, and a culturally sound source is formed. People who shop in all the hustle, chirp, and dynamism of the bazaar present the simple versions of the sections of life. This pure reality is conveyed in the productions of the artist, who is in a cultural and social structuring. In the works of the artist who is sensitive to the cultural values of the society of which he is a member, these areas resonate with a subjective point of view. In Contemporary Turkish Painting Art, many artists who produce works on the theme of the bazaar with their valuable works are encountered. A selection among these valuable names is discussed in the study. Bazaar-themed works were examined within the framework of their cultural dimensions and the plastic approach of the artist. Artists, who make cultural documentaries with their works, have carried out their works according to their stylistic features. The images belonging to cultural values in his fiction are given by being developed in their subjective sensitivities. While some works feel a moving, entertaining, enthusiastic, and dynamic approach, in some works the struggle against the difficulties in life and the struggle for existence in life are presented with a dramatic understanding. The works that differ from each other in terms of both plastic and fictional structure have found form in the subjective styles of the artists. These valuable works produced by representatives of Turkish painting constitute the output of a cultural archive. Through these works, a valuable and rich legacy is left to be passed on to the next generations. 